\title{
Histological and Ultra Structural Alterations of Gills of Freshwater Fish Channa punctatus (Bloch), On Exposure to Pesticide, Sevin
}

\author{
Deepasree .M .I ${ }^{1}$, M. S. Rajendran Nair ${ }^{2}$ \\ P.G Department of Zoology and Research centre, Mahatma Gandhi College, Thiruvananthapuram, India
}

\begin{abstract}
Carbaryl (1-naphthyl methyl carbamate) is a carbamate pesticide. It is a white crystalline solid commonly called Sevin. The present study deals with the deleterious effects of 10.56ppm Sevin on the histopathological and ultra structural levels of the gills of Channa punctatus $\left(1 / 10^{\text {th }}\right.$ of LC $\left.5096 \mathrm{hrs}\right)$.The histopathology of gill was studied under light and scanning electron microscopy. Sevin is a wide-spectrum carbamate pesticide which controls over 100 species of pests. The gills of Channa punctatus exposed to Sevin exhibited lamellar fusion at the tip of gill filaments. In addition, a few aneurisms were also observed in gill lamellae. The gills showed curved secondary gill filaments resulting in distension of the lamellae and the epithelial layer detached completely from the central portion of gill lamellae.
\end{abstract}

Keywords: Channa punctatus, Sevin, Aneurism, epithelial layer, Carbamate

\section{Introduction}

The development and application of pesticides for the control of a wide variety of pests is one of the main factors of Green Revolution. Pesticides control pests in agricultural crops, but when it reaches the aquatic habitat, affect the non target organisms especially fishes. Fishes are particularly sensitive to the pesticidal contamination of water. Hence, these chemical pollutants, when enter into the body of fishes may significantly damage certain physiological and biochemical process and produce serious abnormalities in its organ systems and leads to the extinction of species. So, the effects of pesticides on fishes are of great concern.

Sevin is also toxic to non target aquatic organisms especially fishes. Carbamate is reversible inhibitors of the enzyme acetyl cholinesterase. They interfere with the cholinergic nervous system and cause death because the effects of the neurotransmitter acetylcholine cannot be terminated by carbamylated acetyl cholinesterase. (Wang, et al., 2012). Sevin is also found to be a neurotoxin (Branch_ and Jacqz, 1986). Sevin is extremely toxic to aquatic and estuarine invertebrates (Rani, et al., 1990).

The experimental species selected for the present investigation is Channa punctatus and it is an ideal candidate for water toxicity studies. This is a fresh water fish and was abundantly seen in paddy fields and marshy areas. Now in Kerala, the species is very scarcely available. Due to extensive usage of pesticides in rubber plantations and other agricultural fields, the exposed non target organisms are in a source of concern. Therefore it seems essential to study the lethal toxicity and stress of such environment pollutants on Channa punctatus so as to formulate the strategies for safe guarding aquatic organisms.

Gill is the main osmoregulating organ in fishes, and it is highly sensitive to many factors, including stress, pollution and changes in the salinity of environment.

\section{Materials and Methods}

Adult specimen of healthy Channa punctatus of both the sexes, measuring average length $14.18 \pm 1.03 \mathrm{~cm}$, weight 41.6 $\pm 7.9 \mathrm{gm}$ were collected using cast net from "Chirakadavu pond" at Neduvathoor, Kottarakara(Taluk),Kollam(Dist.) The collected fishes were transported to the laboratory in aerated containers. Fishes were treated with $2 \% \mathrm{KMnO} 4$ solution for 15 minutes to remove external contamination and kept in tanks having capacity of 25 litres filled with 20 litres of well water, and acclimatized for 15 days with continuous aeration and fed with dry shrimps and pieces of earthworms; the water was renewed in every $24 \mathrm{hrs}$.

Ten fishes were taken both in control and treated tanks. The physicochemical parameters of water in which the fishes were kept were analyzed prior to setting up of the experiment and during the course of experiment.

Bioassay experiments have been organized as the standard method for the measurement of toxicity (APHA.2005). Acute toxicity tests serves as a basic tool for understanding the limiting effect of various chemicals on organisms. Such tests have the added benefits that they can be conducted easily and have a discrete endpoint. The median tolerance limit or $\mathrm{LC}_{50}$ proved to be a reliable measure for the establishment of water quality criteria.

The test solution was prepared from Sevin, Manufactured by Parikh Enterprises Ltd. The Sevin itself was used as stock solution. After the preparation of stock solution, the different concentrations of the test solution were prepared by serially diluting the stock solution.

Ten healthy individuals of Channa punctatus were introduced into the tank with utmost care. Control tanks were also setup during the experiment and also maintained at the same conditions as that of the experimental but tap water instead of test solution. Pure tap water which was kept overnight was used for keeping the fishes throughout the

Volume 5 Issue 6, June 2016 www.ijsr.net 


\section{International Journal of Science and Research (IJSR) \\ ISSN (Online): 2319-7064 \\ Index Copernicus Value (2013): 6.14 | Impact Factor (2015): 6.391}

experiment. The water level in the tank was maintained at the same level throughout the experiment.

Observations continued for a period of 96hrs. A fish was considered dead when its respiratory activity ceases and it did not respond to the external stimuli. Care was taken to remove the dead fish from the test containers because this might deplete the level of dissolved oxygen and affect the other fishes. The activities of the fishes such as swimming, breathing, mode of distress, and death were recorded throughout the period of observation.

Median lethal concentration $\left(\mathrm{LC}_{50}\right)$ was calculated by following a computerized program namely SPSS/Windows (SPSS.10.0.LNK) for probit analysis.

The dead fishes were sampled by using nylon hand net without unduly disturbing the rest of the fish in the tank. The collected samples were fixed properly for the further histopathological analysis.

\section{Results}

The LC50 of Sevin for 96 hrs of exposure was calculated as $10.56 \mathrm{ppm}$ through the probit analysis.

The toxic exposure of Sevin induced severe histopathological alterations in the gills of Channa punctatus. In Channa punctatus there are four pairs of semicircular gill arches. The surface of gill lamellae is having blood sinusoids which are necessary for effective gas exchange during respiration.

The gill of Channa punctatus consists of primary lamellae arranged in double rows on either side of a central rod, projecting on the lateral sides of which are a series of alternately arranged secondary lamellae.

The exposure of Sevin persuaded histopathological alterations in the normal gill architecture of Channa punctatus. After $96 \mathrm{hrs}$ of exposure to $10.56 \mathrm{ppm}$ concentration of Sevin, the gill tissues of Channa punctatus revealed large inter-lamellar space, necrosis, lamellar fusions enlarged secondary gill lamellae, curved secondary gill filaments resulting in distension of the lamellae.

An abnormal swelling of tip of secondary gill lamellae and their erosion were observed. Rupture of capillaries at the tip of secondary gill lamellae releasing blood cells was also seen at many places. Haemorrhage between gill filaments, dilation in blood vessels of gill filaments (Telangiectasis) in secondary lamellae was observed.

A large number of blood cells accumulated in secondary gill lamellae and resulted in enlargement of gill lamellae. Consequently the separation of epithelial cells from the basement membrane and fusion of secondary gill lamellae were also observed. The gills also exhibited lamellar fusion at the tip of gill filaments. In addition, a few aneurisms were also observed in gill lamellae. In some areas, epithelial hyperplasia, swelling of epithelial cells and bronchial epithelium disorganization were evident. Furthermore, the epithelial layer detached completely from the central portion of gill lamellae.

Typical chronic changes occurred in the gills surface; hyperplasia, epithelial lifting, cell swellings congestions, the bending of secondary lamellae, formation of oedematous space between the layers of epithelium which may become infiltrated with red blood cells. Gill hyperplasia was observed in the primary epithelial cells. Then, the whole lamellar epithelium was found to be degenerated and the lamella lost its rigidity.

\section{Discussion}

The gill of exposed fish showed several histopathological alterations like complete fusion of lamellae coupled with hyperplasia, hypertrophy and epithelial lifting, necrotic, shrinked and curved lamellae. Due to direct toxic effect of the pesticides on the gill tissue can be lamellar and interlamellar epithelial necrosis (Jaya.K and Shettu.N., 2015).

Epithelium lifting was observed in the Sevin treated gills. Epithelial lifting increases the distance between blood and epithelial layer and thus decrease velocity of penetration of the molecules of Sevin in to blood. So the epithelial lifting can be considered as a defence mechanism adopted by fishes to slow down the penetration of pesticide through lamellar epithelium. The epithelial lifting in gills decelerate oxygen uptake and produce dysfunctional gills, and eventually asphyxiate the fish (Kumar et al., 2010).

In the present study on exposure to Sevin the gill of Channa punctatus showed severe histopathological changes, the gill lamellar epithelium of the fish got degenerated and the lamellar epithelium separated from the lamellar tissue, the osmoregulatory function got disturbed, and the fish became hypoxic. Same observations were reported by Van Heerden et al.,(2004),Abdel Tawwab et al.,(2007),Camargo and Martinez.,(2007) and Simmonato et al.,(2008), on their studies with copper, phenol and diesel exposure to the fish Channa punctatus

Clubbing of the ends of the gill lamellae and a tendency of fusion of adjacent lamellae were the general effects observed on gills due to Sevin exposure. The lamellar fusion can be a protective mechanism as it helps in reducing the surface area of gills, so that the gill surface area exposed to pesticide also gets reduced (Ortiz, J., 2003). These pathological changes in the gill lamellae may either be an adaptive response to prevent the entry of the pollutants thorough the gill surface or a pathological reaction of pesticide penetrated into the gills due to increased capillary permeability of gill lamellae (Olurin, k., 2006).

Gill lesions associated with the lamellar aneurysm were observed in prevalence in all treatment groups. The lesions may be due to the disturbance of blood flow in the blood channels. Similar histopathological lesions have been reported by Campagna, A., (2007) in Danio rerio juveniles, in chlorpyrifos exposed Channa punctatus (Yogitha Devi and Abha Mishra 2013) and in Channa punctatus due to Glyphosate based herbicide exposure (Senapati et al., 2009). 


\section{International Journal of Science and Research (IJSR) \\ ISSN (Online): 2319-7064 \\ Index Copernicus Value (2013): 6.14 | Impact Factor (2015): 6.391}

As fish gills are the critical organs for their respiratory and osmoregulatory functions, the injuries in gill tissues were observed to reduce the oxygen consumption and disrupt the osmoregulatory functions of the fish.

\section{Conclusion}

Water is a renewable resource and a universal solvent. This unique property of water makes it susceptible to many types of pollutants. Most of the water bodies are polluted. Water is the most valuable natural resource, essential for all organisms. Water is polluted mainly by domestic, agricultural and industrial effluents. The water pollution directly affects the aquatic flora and fauna and leads to their extinction or they become endangered. The fish under the study Channa punctatus was once present abundantly in the water bodies of Kerala, now become endangered.

In this context, the present study is undertaken to investigate the impact of commonly used pesticide Sevin on Channa punctatus so as to find the reason for its endangering status in water bodies on the embankments of Rubber plantations and the pesticidal impact on the internal organs of this fish, which are leading to the death and endangering status of the fish Channa punctatus in most of the aquatic bodies in Kerala.

\section{Acknowledgement}

I am extremely grateful to the Department of Zoology, M.G College, Trivandrum .I also express my sincere gratitude to the Electron Microscopy Division of SreeChithira Trirunal Institute of Medical Science and Technology (SCTIMST), Trivandrum.

\section{References}

[1] Abdel-Tawwab, M., Abdelghany, A.E., Ahmad, M.H. 2007. Effect of diet supplementation on water quality, phytoplankton community structure, and the growth of Nile tilapia, Oreochromis niloticus, Common carp, Cyprinus carpio, and Silver carp, Hypophthalmichthys molitrix, polycultured in fertilized earthern ponds. J.Appl.Aquacult. 19(1):1-24.

[2] APHA. 2005. Standard methods for the examination of water and waste water. $21^{\text {st }}$ Edn. Washington, D.C.

[3] Branch, R.A and Jacqz, E. 1986. Subacute neurotoxicity following long-term exposure to Carbaryl. Am. J. Med.80:741-5.

[4] Camargo, M.M. and C.C.Martinez.2007. Histopathology of gills, kidney and liver of a neo tropical fish caged in an urban stream. neotropic. icthyol. 5:327-336.
[5] Campagna, A., Eler, M., Fracacio, R., Rodrigues, B. and Verani, N. 2007. The toxic potential of aldrin and heptachlor on Danio rerio juveniles (Cypriniformes, Cyprinidae). Ecotoxicol. 16: 289- 298.

[6] Jaya, K. and Shettu, N. 2015. Transmission electron microscopic study of gills of freshwater fish Channa punctatus (Bloch) exposed to the toxicity of cypermethrin. Journal of Chemical and Pharmaceutical Research. 7(9):698-701.

[7] Kumar, M., Prasad, M. R., Srivastva, K., Tripathi, S., and Srivastva, A. K. 2010. Branchial histopathological study of Catfish Heteropneustes fossilis following exposure to purified neem extract, Azadirachtin. World Journal of Zoology. 5(4), pp.239243.

[8] Olurin, K., Olojo, E., Mbaka G. and Akindele, A. 2006. Accumulation and Histopathological responses of the gill and liver tissues of Clarias gariepinus fingerlings to the herbicide, glyphosate. African $J$. Biotechnol. 5: 2480-2487.

[9] Ortiz Juan, B., Gonzalez de Canales, M.L. and Sarasquete, C. 2003. Histopathological changes induced by lindane $(\gamma-\mathrm{HCH})$ in various organs of fish. Sci. Mar. 67:53-61.

[10] Rani, S., Shaik Dawood, A. and Ramasamy, M. 1990. Toxicity of a carbamate fungicide, cuman to an edible, freshwater fish, Sarotherodon mossambicus (Peters). J. Aquor. 3 (1): 29-36.

[11] Senapati, T., A. K. Mukerjee and A. R. Ghosh. 2009. Observations on the effect of glyphosate based herbicide on ultra-structure (SEM) and enzymatic activity in different regions of alimentary canal and gill of Channa punctatus (Bloch). Journal of Crop and Weed. 5(1): 233-242.

[12] Simonato, J.D., Guedes, C.L.B. and Martinez, C.B.R. 2008. Buochemical, Physiological and histological changes in a Neotropical fish Prochilodus lineatus exposed to diesel oil. Ecotoxicol.Environ.Saf. 69:112-120.

[13] Van Heerden, D., Vosloo, A., Nikinmaa, M. 2004. Effects of short-term copper exposure on gill structure, metallothionein and hypoxia-inducible factor-1a (HIF1a) levels in rainbow trout (Oncorhynchus mykiss). Aquat. Toxicol. 69, 271-280.

[14] Wang, Y., Wang, L., Zhu, Z., Ma, W., and Lei, C. 2012. The molecular characterization of antioxidant enzyme genes in Helicoverpa armigera adults and their involvement in response to ultraviolet-A stress. J. Insect Physiol. 58:1250-1258.

[15] Yogita Devi and Abha Mishra. 2013. Histopathological Alterations in Gill and Liver Anatomy of Fresh Water, Air Breathing Fish Channa Punctatus after Pesticide Hilban (Chlorpyrifos) Treatment. Adv. Biores. Vol4 (2): 57- 62. 


\section{International Journal of Science and Research (IJSR)}

ISSN (Online): 2319-7064

Index Copernicus Value (2013): 6.14 | Impact Factor (2015): 6.391

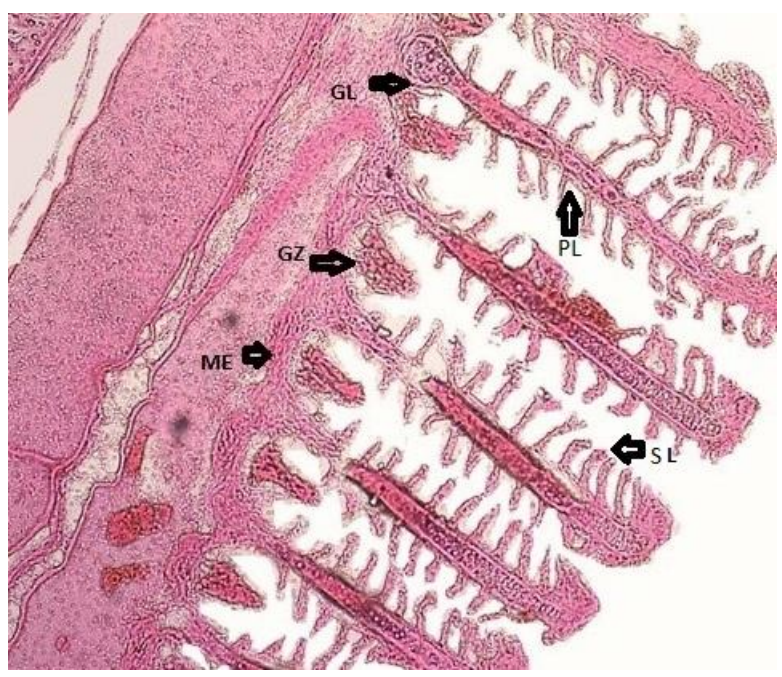

Figure 1: Gill Normal Structure.

GL-Growing Lamellae, PL=Primary Lamellae, GZ-Growth Zone, ME-Mucosal Epithelium, SL-Secondary Lamellae (100 X).
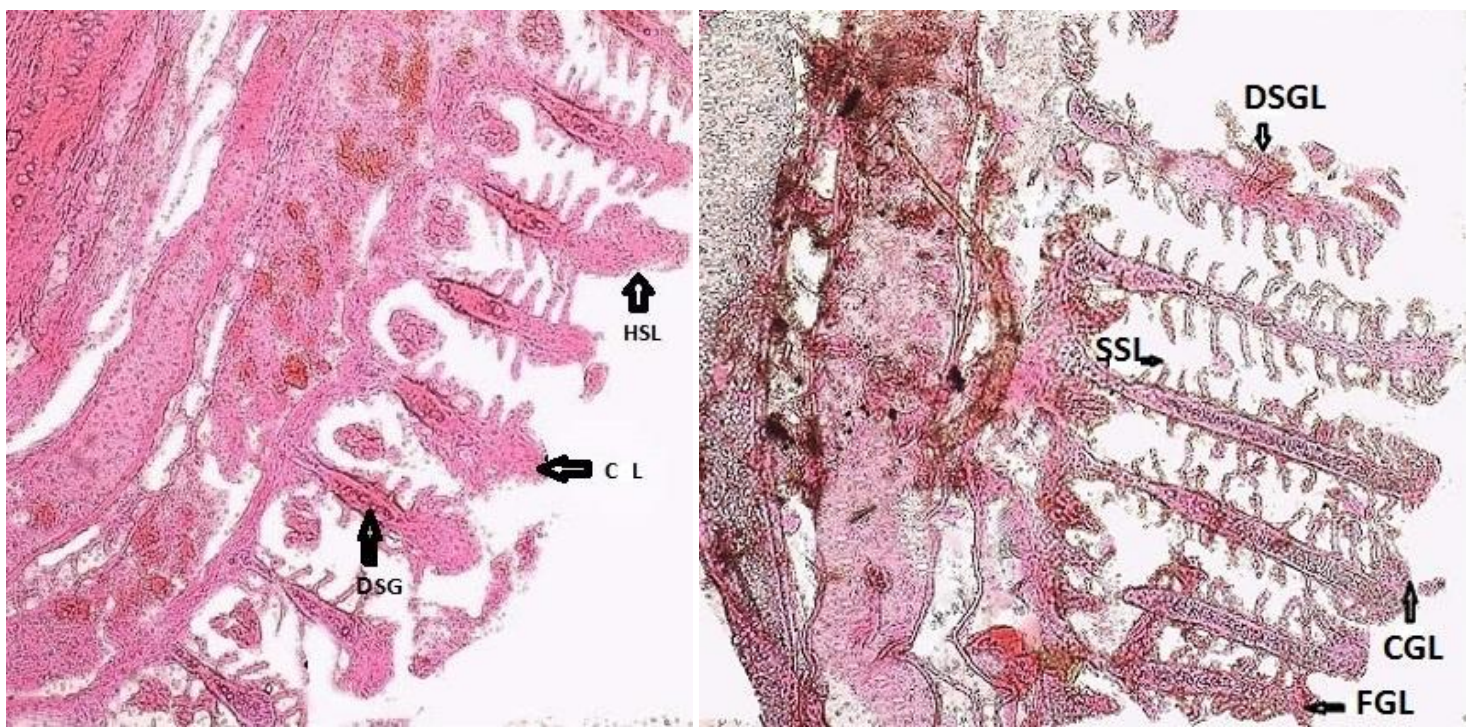

Figure 2 and Figure 3: Gill Treated with Sevin

HSL-Hypertrophy of Secondary Lamellae, CL-Club Shaped Lamellae, DSGL-Degenerated Secondary Gill Lamellae, SSLSpiked Secondary Lamellae, CGL-Curved Gill Lamellae, FGL-Fused Gill Lamellae. (100X)

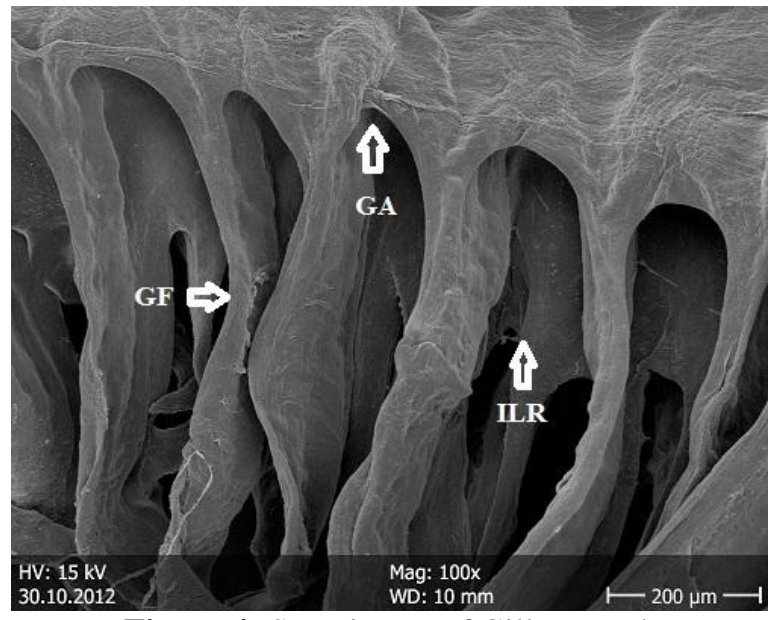

Figure 4: SEM image of Gill Normal

GA-Gill Arch, GF-Gill Filament, ILR-Inter Lamellar Region

Volume 5 Issue 6, June 2016 www.ijsr.net

Licensed Under Creative Commons Attribution CC BY 
International Journal of Science and Research (IJSR)

ISSN (Online): 2319-7064

Index Copernicus Value (2013): 6.14 | Impact Factor (2015): 6.391

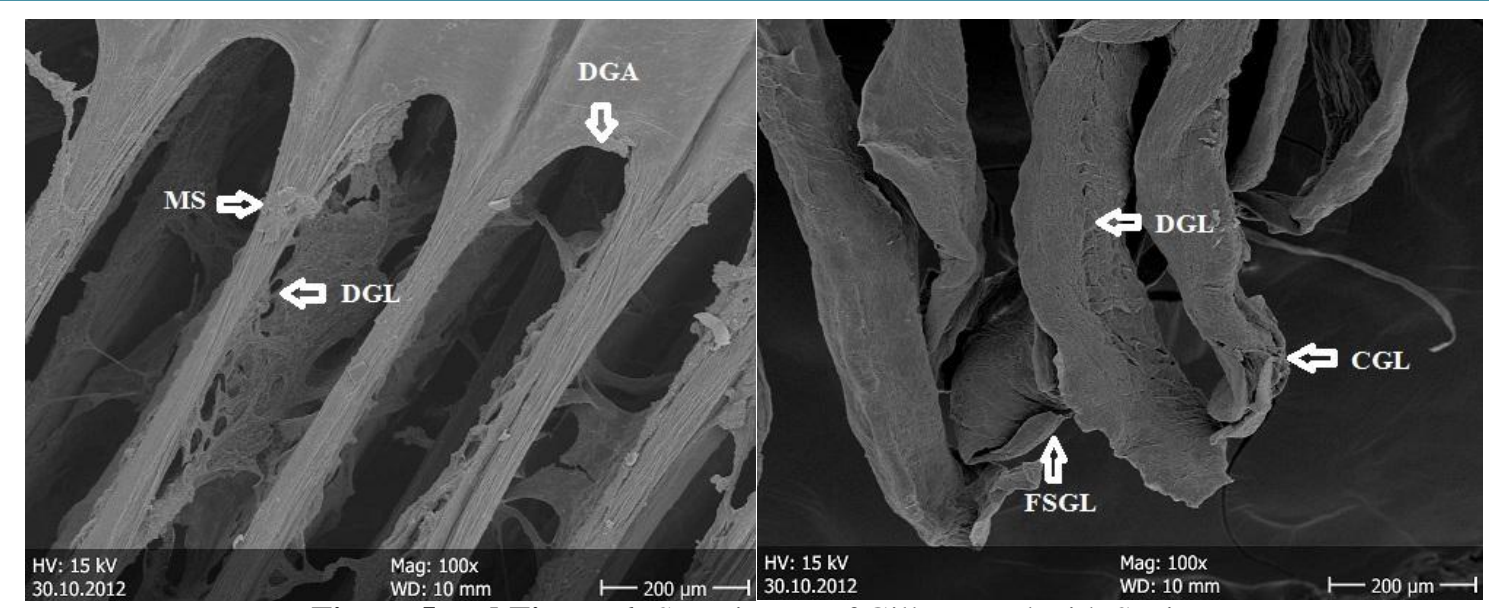

Figure 5 and Figure 6: SEM image of Gill Treated with Sevin

MS-Mucus Secretion, DGL-Degenerated Lamellae, DGA-Degenerated Gill Arch, FSGL-Fused Secondary Gill Lamellae, CGL-Curved Gill Lamellae.

Volume 5 Issue 6, June 2016 www.ijsr.net 